Instructions for authors, subscriptions and further details:

\title{
Working with Men: A Gender-Sensitive Practice Model
}

\section{Glenn Stone ${ }^{1}$}

1) Ball State University, United States of America

Date of publication: February $21^{\text {st }}, 2020$

Edition period: February 2020 - June 2020

To cite this article: Stone, G. (2020). Working with Men: A Gender-Sensitive Practice Model. Masculinities and Social Change,9(1), 28-52. doi:

10.17583/MCS.2020.4277

To link this article: http://doi.org/10.17583/MCS.2020.4277

\section{PLEASE SCROLL DOWN FOR ARTICLE}

The terms and conditions of use are related to the Open Journal System and to Creative Commons Attribution License (CC-BY). 
pp. $28-52$

\section{Working with Men: A Gender- Sensitive Practice Model}

\section{Glenn Stone}

Ball State University, United States of America

\section{Abstract}

This article provides an overview of providing counseling services with men in a manner that is gender sensitive. Initially, the historical background of working men is provided. Next, a conceptual framework is provided for counseling with men from the work of Norman and Wheeler (1996). This framework contains consideration of how men are "like some others", "like all others", and "like no others". The article then lists five challenges that must be addressed by those counseling men with suggestions for counselors to overcome each of these challenges.

Keywords: men, gender-sensitive practice, behavioral health 
pp. $28-52$

\section{Ayudando a los Hombres: Un Modelo de Práctica Sensible al Género}

Glenn Stone

Ball State University, United States of America

\section{Resumen}

Este artículo proporciona una descripción general de la prestación de servicios de asesoramiento con hombres de una manera sensible al género. Inicialmente, se proporcionan los antecedentes históricos de trabajar con hombres. A continuación, se proporciona un marco conceptual para el asesoramiento con hombres del trabajo de Norman y Wheeler (1996). Este marco contiene la consideración de cómo los hombres son "como otros", "como todos los demás" y "como ningún otro". El artículo enumera cinco desafíos que deben abordar los consejeros con sugerencias de consejeros para superar cada uno de estos desafíos.

Palabras clave: hombres, práctica sensible al género, salud del comportamiento 



\section{Glenn Stone - Working with Men}

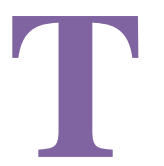

he study of gender has historically focused on how the various socially proscribed roles that exist in society impact and affect women. In regard to the fields of counseling and therapy around issues of behavioral health, there has even been the suggestion that traditional interventions may act to inhibit changes in social roles for women. Chesler (1972) suggested that therapy could actually serve as an agent of social control. This view was supported by Hook (2003) over thirty years later. In regard to women, those who engage in traditional "passive" behaviors could be viewed as "healthy" while those who engage in more "assertive" behaviors could be viewed as "socially deviant" and as "sick" and in need of treatment. In effect, therapy efforts may work to maintain a certain level of the status quo in gender relationships. This may be seen through the way that practitioners may automatically assume that child-rearing or household maintenance tasks are the responsibility of the woman in a family. This might also be manifested in rather subtle ways such as how practitioners phrase questions or who is even asked the question. For example, when asking about the bedtime of a five-year-old, the practitioner may automatically direct that question to the mother. If the mother is unable to respond to such questions, she may even be labeled as "a bad mother." This type of questioning may extend to the general emotional climate of the family or other related issues. As one can see, this type of questioning may reinforce the idea that women are the ones to be viewed as the family "nurturer" or "caregiver" and that she may have no other relevant roles. It may detract from the women's roles outside the home, such as "breadwinner." It could also suggest that the father is not involved in a nurturing and/or caretaking capacity within the family. It would seem appropriate to consider these types of practitioner behaviors as "gender-biased" and not examples of "gender-sensitive" practice. It is the purpose of this paper to provide a contextual framework for working with men that does provide for the special needs and challenges that men present when they do seek counseling. 


\section{Gender Sensitive Practice with Men: Background}

Collins, Jordan, \& Coleman (2009) note that "gender-sensitive" practice "advocates sensitivity to the problems created when rigid, traditional gender roles are assigned to family members" (p. 201). It seems clear from the previous examples that women have long been victims of the application of these inflexible, traditional gender roles. However, beginning in the 1980s men's behavioral health issues became more prominent and gender studies slowly began to explore the ways in which gender role constraints have also affected men (Levant \& Pollack, 1995). As a result, researchers and practitioners started to consider the ways in which traditional counseling and therapy interventions may also be gender insensitive towards men, that is, workers may at times apply rigid, traditional role expectations to men just as they have women.

In a study by Robertson \& Fitzgerald (1990), practicing counselors and therapists were randomly assigned to view one of two versions of a videotaped role-play of a depressed male client (portrayed by a professional actor). The tapes were identical except for the client's occupational and family roles, which were portrayed as either gender-traditional or nontraditional. After viewing the tapes, the practitioners evaluated the client on various dimensions, specified a diagnosis, and generated a treatment plan. The researchers found that practitioners were much more likely to diagnose severe psychopathology when a male chose not to engage in the stereotypical "good provider" role.

In a study by Vogel, Epting, \& Wester (2003), it was found that both male counselors and female counselors consistently perceived the presenting issues of male and female clients along rather traditional gender lines. They found that "the themes of 'vulnerability' and 'paying attention to how much the client asserts [themselves]' were more pronounced for female clients than for the male clients" (p. 137). In addition, "the themes of 'being stuck' and 'paying attention to how much the client is connected to others' were more pronounced for male clients than for female clients" (p. 137). As can be evidenced, the differences in the workers' descriptions seemed to occur in traditional gender role directions. Vogel et al. (2003) point out that the idea of 


\section{Glenn Stone - Working with Men}

vulnerability is similar to findings that counseling, and comforting are seen as more suitable for women (e.g., Wilcox \& Forrest, 1992). The focus on men's connectedness is consistent with the widely held belief among counselors that male counseling clients usually need to work on expressing their emotions, whereas female clients usually do not (e.g., Heatherington, Stets, \& Mazzarella, 1986; Knudsen-Martin, 2013). In summary, Vogel et al. note that "although these differences may reflect the workers' desire to help clients (i.e., asserting self, building connections), they may be partly due to the counselors' subscribing to traditional gender role beliefs rather than overall therapeutic goals" (2003, p. 138).

\section{Gender Sensitive Practice with Men: Conceptual Framework}

Norman and Wheeler (1996) in their seminal work on gender-sensitive practice, propose a practice model for practitioners that they assert is applicable across disciplines. They maintain that much of the theory and practice literature is filled with "unidimensional" models of assessment and intervention. This "one size fits all" mentality of assessment and intervention is not appropriate for gender-sensitive work with women or men. As they state:

Neither females nor males should be subjected to unidimensional, inflexible models of psychosocial assessment and intervention... Practitioners must keep in mind that each individual is unique, with unique experiences, perceptions, feelings, and behaviors, and yet has much in common with other human beings. (p. 208)

Norman and Wheeler (1996) suggest that practitioners should remember that each individual is: (a) like no other human being, (b) like some others (other females or other males), and (c) like all others in the human community (female and male). These three concepts form the basis for their "threedimensional" approach to working with both genders. 
Figure 1 illustrates their schema and provides an initial conceptual framework within which practitioners can adapt their current assessment and intervention models. As Figure 1 clearly demonstrates, there are two fundamental errors that workers may find themselves making with clients.

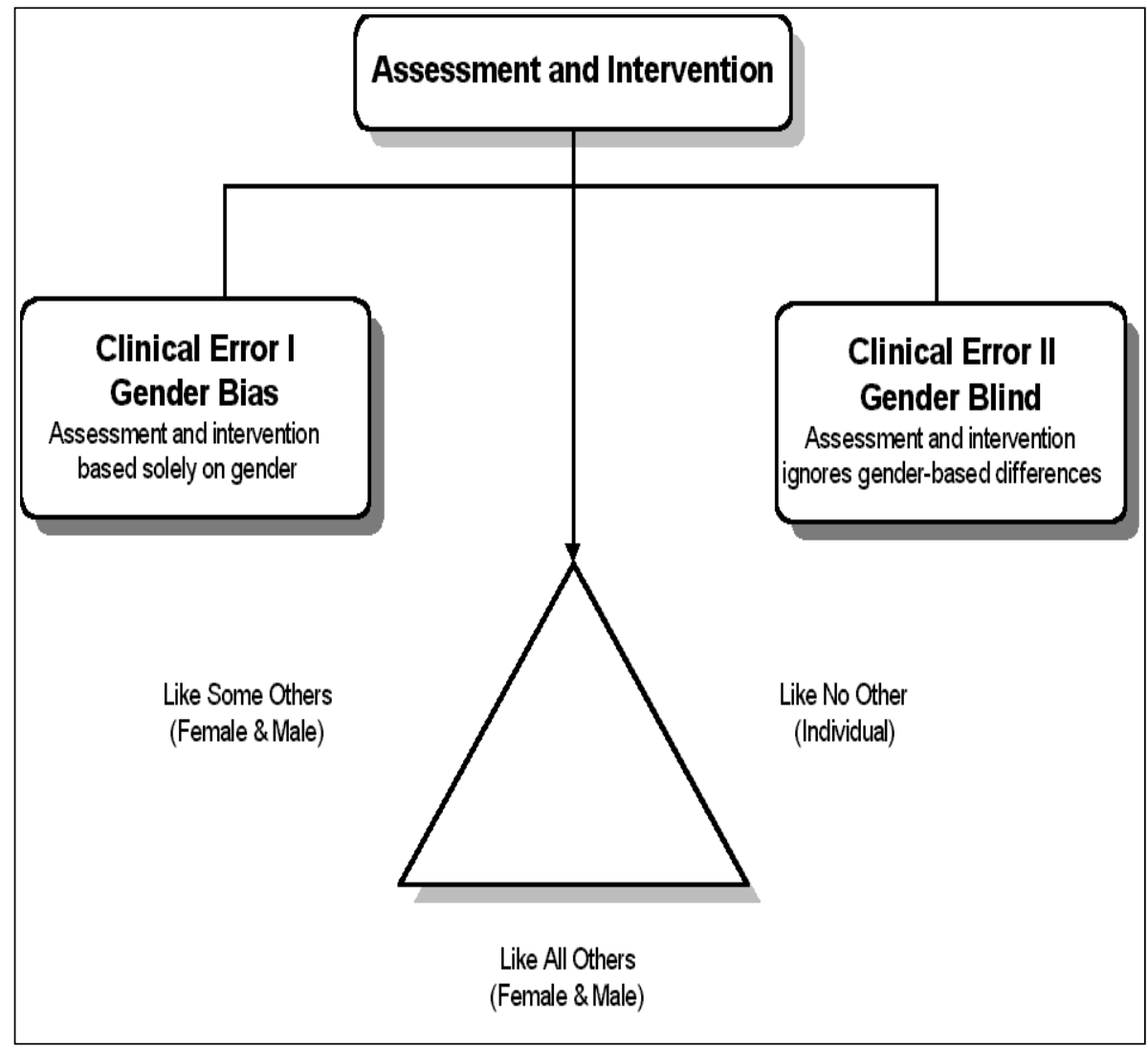

Figure 1.Gender-Sensitive Practice Model

The first error, Gender Bias, refers to the tendency for some workers to only see gender issues when they are completing assessments and intervention 


\section{Glenn Stone - Working with Men}

plans. If a worker uses this type of selective perception, they will be more likely to make assumptions that are incorrect regarding the basis of the client's behaviors and issues by assuming the cause of the issues is related to gender differences when in fact the issues are based on some other issue. For example, a worker may assume that a divorced father experiencing depression is feeling that way because he has lost his power as a male when in fact the emotion may be more connected with feelings of loss over having less contact with his children. Eriksen \& Kress (2008) note the continued existence of gender biases exhibited by both male and female practitioners toward their clients.

The second type of error, Gender Blind, is failing to recognize that gender is in fact the real issue underlying the client's dilemma. An example of this view can be found in the work on "intimacy" and the assertion that perhaps there is more than one definition of "intimacy," a female defined version and a male-defined type (Baumeister \& Sommer, 1997; Patrick \& Beckenbach, 2009). Practitioners often apply the concept of female intimacy when evaluating male behaviors, when in fact the worker may be dealing with true gender differences about what how one defines and enacts "intimacy" rather than a "healthy" versus "unhealthy" typology of intimacy.

These two types of clinical errors lead to misunderstandings and inappropriate interventions. They have rippling effects throughout the three dimensions discussed by Norman and Wheeler (1996). We will explore each of these three dimensions and the issues related to gender-sensitive work with men within each.

\section{Like No Other}

One of the first issues to consider when assessing and intervening with men is to remember that they are unique individuals with their own issues and perceptual reality. A man's life may be more different than similar to the lives of others (women, mothers, children, etc.). The fact that the client is a man does not mean that he shares the same opinions, views, perceptions as other men. Norman \& Wheeler (1996) assert that workers must "personalize assessment data and avoid the pitfalls of categories, stereotypes, and 
classifications" (p. 209). Unfortunately, the research and practice worlds are filled with negative stereotypes about men. For example, one need only review recent literature related to the area of the family to understand the problem. One of the more frequent portrayals of men in research of the family is that of "victimizer." This type of research examines situations in which men are perpetrators of incest and physical and emotional abuse (e.g., Baum, 2016; Fong \& Walsh-Bowers, 1998; Veach, 1997). This is not to say that these events do not occur, nor that they should not be researched. Every effort needs to be made to eliminate these types of harmful behaviors. The problem is that, until recently, there has been little offered as a contrasting view of men and men in the literature on the family. It may be too easy to simply overgeneralize from such negative studies. For example, based upon some of the research, workers may believe that most men have unhealthy motivations for wanting to stay connected to their children after divorce and separation (e.g., Toews, \& Bermea, 2017). A worker who desires to provide the best possible services to men will need to put aside such pre-conceptions and realize that it is vital to listen to the father's concerns with an open mind and open heart.

\section{Like Some Others}

According to Norman \& Wheeler (1996), "like some others" means that everyone can be identified as belonging to various subgroups or categories. For example, gender is one of those categories and it is therefore appropriate for practitioners to consider it in assessments and interventions. Within this context, it may be acceptable to cautiously make some "generalizations" based upon gender. There are both biological and socialization factors which contribute to commonalities among men. Of course, the debate is "which ones" and to "what degree?" When we engage in such generalizations, we must be constantly aware that there is a thin line between "helpful" generalizations and "unhelpful" stereotyping.

To gain a better understanding of the "helpful" variety of generalization it may be of assistance to consider some of the "commonalities" that have been observed in the area of parenting and how men tend to perform their parenting 


\section{Glenn Stone - Working with Men}

role as compared to women. Research has shown that men tend to interact with their children in a way that is different than mothers. For example, men tend to spend a greater portion of their time with children engaging in playful interactions, even when conducting caretaking activities (Fish, New, \& VanCleve, 1992; Musick, Meier, \& Flood, 2016). In a multigenerational study by Snarey (1993), several commonalities in the way that men related to their children were observed among men. These similarities included such behaviors as: playing games, going on outings, providing enrichment programs and lessons, teaching athletic skills, and verbal play. These types of activities seemed to have positive developmental influences for children. In practical terms, a worker may find it necessary to think twice before judging a father harshly for "only playing with the kids." Grossmann, et al., (2002) found similar results in their study of fathers over a 16 year period of parenting.

\section{Like All Others}

Finally, we must acknowledge that as human beings we share common issues that make us "like all others." There are commonalities that connect us all. Norman \& Wheeler (1996) assert that most assessments and intervention models do an adequate job of addressing this third dimension. Whether we are talking about solution focused models of intervention or cognitive-behavioral models, most theoretical orientations are quite proficient at identifying our similarities.

Hyde (2005) puts forth a "Gender Similarities Hypothesis" following her meta-analysis of 46 studies on gender difference on various psychological and physical factors. She found that many purported differences are contextual in nature. For example, she notes studies in which the contextual nature of the research impacted the performance of men and women on math scores in such a way that the "myth" of women being less skilled in math was not observed. In another example she also noted the power of contextual situations to influence the helping behaviors of men and women. It is important to note that she does relate a few exceptions to this hypothesis. She found differences in 
some motor abilities (e.g., throwing distance) and some characteristics of sexuality, which showed significant differences across genders. She also reported a moderate difference in aggression.

In summary, Norman \& Wheeler's framework for establishing gendersensitive practice is an important starting point for workers to consider before they begin working with men. The framework reminds workers to keep an open mind to their own gender biases and preconceptions that might interfere with their work with men. It also provides a useful framework for developing highly individualized assessment and intervention strategies for men. This conceptual model can be combined with other sources of useful information such as the special challenges in working with men. The gender sensitive practice model combined with an understanding of these challenges can lead to better intervention planning. We shall now review these special challenges and some approaches to take with men.

\section{Working with Men: A Gender Sensitive Approach}

In this section we will identify the various challenges that a worker may face when attempting to provide services to men as noted by researchers in the field. Each challenge noted will include the relevant research to that challenge. Within each challenge we will discuss various techniques that might help overcome the particular challenge.

\section{Challenge 1: Fear of Being Seen as a Failure}

A typical obstacle for men seeking help is the perception that they have that others may view them as a failure (Jordan, 1993). It is often the case that men will simply hold the view that it is unacceptable to even admit to having problems. In essence, it would be "unmanly" to seek help from anyone (Seidler, Rice, River, Oliffe, \& Dhillon, 2018).

Efforts to overcome this barrier to treatment may involve some form of helping men to "save face." Scher (1979) notes that it is imperative that workers be sensitive to and understand the pride of the male client. In social 


\section{Glenn Stone - Working with Men}

work practice, we call this "starting where the client is." Every effort should be made to encourage the male client to talk about the "fear" of being seen as weak or a failure. The initial stages (and throughout) are especially important times to encourage the father to talk about strengths as well as areas to improve. The strengths perspective is a way of equalizing the helping relationship and of encouraging clients to look inward to discover their own resources (Saleeby, 1992). As a practitioner, it is very helpful to identify strengths that the man may possess and make it a point to encourage him to expand on these strengths in order to lessen his feelings of inadequacy. For example, a man entered into counseling who worked as a farmer. The worker made a point early on in the sessions to acknowledge this vocation as a strength and at one point the worker posed a "gardening" problem to the client that one of the worker's colleagues was experiencing. Allowing the client to feel "helpful" reduced his sense of failure and allowed a degree of "facesaving" that made further work possible (Heppner \& Gonzales, 1987).

\section{Challenge 2: Difficulty in Identifying and Expressing Emotions and Emotional Processes}

It could be said that the male socialization process has been very successful in producing men who can achieve at business, sports, and other competitive activities. However, the trade-off is that men often learn "not to feel," or to deny or to repress their emotional responses to life's events (Heppner \& Gonzales, 1987; Holmes, 2015). There is a degree of "functionality" in "not feeling" when it comes to beating out another competitor for a top-paying job in the company. Feelings of empathy might be viewed as "unnecessary baggage" that could hold back the competitive male from advances in his career. However, "not feeling" can take its toll in the interpersonal domain of a man's life.

Being taught "not to feel" and that it is wrong to express "weak" (e.g., sadness, compassion, warmth) emotions can certainly reduce a man's capacity to adjust to the range of challenges he may face in his personal and professional life. Levant (2011) discusses this problem as a mild form of 
"alexithymia", which literally means "without words for emotions." For example, one man in treatment talked about his suicidal thoughts over a recent event at work in which he was passed over for promotion. Upon further exploration, the worker was able to discover that the father's job performance had been slipping as the result of a debilitating depression related to reduced contact with his children following a divorce. If the worker had taken the client's concerns at face value, they could have spent the entire session talking about the workplace. The skilled worker was able to help the man express his emotions and process how his depression was affecting his job performance.

Efforts to help men deal with their emotional issues can be a challenging task for the worker. At times, it may be necessary to help men establish an "affective vocabulary" (Holmes, 2015) due to their limited expression of emotions. Some workers actually provide their clients with handouts describing various emotional states to facilitate the learning process. It is also important that the worker be skilled in exploring underlying issues that men may carry with them. For example, one divorce male was referred for counseling due to his "problems with anger" toward his former spouse. After developing a rapport and level of trust with the client, the worker was able to help the man discover that beneath his feelings of anger toward his former spouse there existed deeper feelings of fear that he might be hurt and rejected by women in general and that these feelings were long-standing for him. A less skilled worker might have simply focused on anger-reduction techniques that did not address the deeper, more meaningful struggles for this man.

\section{Challenge 3: Reactions to Increased Intimacy in the Counseling Relationship}

This particular challenge results because the worker has been successful in their efforts to develop a working relationship with men (Englar-Carlson, Evans, \& Duffey, 2014; Heppner \& Gonzales, 1987). This represents a bit of a paradox for the worker in that the relationship becomes jeopardized because of the very nature of the success that has developed. The father may experience a sense of fear related to this new-found closeness. In the case of 
male client-female worker situations, the father may confuse this workerintimacy with sexuality. This should not be a surprise given the socialization process for men and the tendency for men to come to believe that this type of closeness is reserved for sexual partners. In the case of male client-male worker, Heppner and Gonzales (1987) suggest that high intimacy levels between males may lead to a range of homophobic reactions.

In general, the best way to deal with intimacy issues within the clientworker relationship is to be direct and honest in discussions of the issues before they even become an issue. These types of discussions can be framed in a way to lessen the man's sense that there is something wrong with him if he starts to experience these reactions. For example, one worker talked with her male client about how often times in counseling relationships clients start to have certain kinds of "intimate" feelings toward their worker. By normalizing and universalizing the feelings, this worker was able to have a productive talk with her male client about worker-client intimacy versus sexual intimacy. It was helpful for the client because he was able to learn from her perspectives and able to identify healthy ways to deal with his emotional reactions as well as learn ways to avoid sexualizing all male-female relationships.

\section{Challenge 4: General "Resistance" to Counseling}

Sometimes men seek help because their friend, spouse, or current lover has threatened them in some way that has led the man to believe that he will lose a significant relationship if he doesn't change (Cusack, Deane, Wilson, \& Ciarrochi, 2004). The threat may even come from an "authority figure" such as the court system that has mandated counseling. In any of these situations, the father may feel a sense of being forced to seek help. Men in this position may show varying levels of opposition to the helping process. Many practitioners have been inclined to label client behaviors which seem to go against the agenda of the practitioner as "resistance" (Hepworth, et al., 1997). The key factor for the worker is that they sense that the client is intentionally refusing to cooperate. Unfortunately, workers may have been too quick to 
apply this label and attribute failure of their work with a client to resistance, when, in fact, the failed intervention may be the result of inappropriate or ineffective helping methods (Hepworth, et al., 1997).

Assistance in working with men who are evidencing a degree of ambivalence about working with professionals may be found in the research on "motivational interviewing." Miller and Rollnick (2002, p. 25) define motivational interviewing as a "client-centered, directive method for enhancing intrinsic motivation to change by exploring and resolving ambivalence" using four basic motivational principles: (1) expressing empathy, (2) developing discrepancy, (3) supporting self-efficacy, and (4) rolling with resistance. At this point we will explore each of these principles as applied to men.

Expressing empathy. For the practitioner, empathy involves seeing the world through the client's eyes, thinking about things as the client thinks about them, feeling things as the client feels them, sharing in the client's experiences. When men feels that they are understood, they are more able to open up to their own experiences and share those experiences with others. Having men share their experiences in depth allows the worker to assess when and where he may need support, and what potential pitfalls may require focus in our meetings with men. When men perceive empathy on a practitioner's part, they become more open to gentle challenges by the worker about a wide range of self-defeating behaviors, attitudes, and emotions. Men can become more comfortable examining their ambivalence about change and less likely to become defensive and hold on to old ideas of blame, anger, etc. In essence, the worker's accurate understanding of the full range of their client's experiences helps to bring about change (Moyers, 2014).

Developing discrepancy. "Motivation for change occurs when people perceive a discrepancy between where they are and where they want to be" (Miller, Zweben, DiClemente, \& Rychtarik, 1992, p. 8). It is critical for practitioners to work with men to develop this situation through helping them examine the discrepancies between their current behavior and future goals. When men come to understand and appreciate that their current behaviors are not leading toward some important future goal, they are more likely to become 


\section{Glenn Stone - Working with Men}

motivated to make important life changes. Of course, practitioners should not develop discrepancy at the expense of the other motivational interviewing principles, but gently and gradually help men to see how some of their current ways of behaving, thinking, and feeling may lead them away from, rather than toward, their self-proclaimed goals. For example, a man was able to change his angry expressions about his former spouse in front of his child when he realized that such outbursts were not really helping to improve his relationship with his child. This recognition of the discrepancy between his goals and current behaviors was a vital step in reducing his resistance to the helping efforts of the worker.

Supporting self-efficacy. As noted earlier, a man's belief that change is possible is an important motivator to succeeding in making a change. As men are held responsible for choosing and carrying out actions to change, workers focus their efforts on helping him to stay motivated and supporting his sense of self-efficacy is a great way to accomplish this therapeutic task (Miller, et al., 1992). Bandura (1962) defines self-efficacy as a personal evaluation of "how well one can execute courses of action required to deal with prospective situations" (p. 122). Men can be helped to develop a belief that they can make a positive change in their life. For example, the worker might ask about healthy changes the male client has made in his past, thus illuminating the skills the client already possesses in their repertoire. It may also be helpful for the worker to share brief examples of other, similar men' successes at changing the same habit or problem. For example, a male client who is feeling a sense of rejection from his partner after arguments might be told of how another man was able to successfully rebuild his relationship with his partner after disputes in the relationship. This type of sharing can help to reduce the feelings of hopelessness experienced by the male client and may assist in reducing his level of resistance about counseling.

Rolling with resistance. When using the techniques of motivational interviewing, the worker does not fight client resistance, but "rolls with it" (Miller et al., 1992). The worker does not challenge a man when he expresses resistant-like comments or behaviors. Instead the worker uses the man's "momentum" to further explore his views. Workers need to remain non- 
defensive and calm when faced with a hostile and resistant male client and avoid confrontation. In managing resistant clients, it is important not to oppose the resistance but to understand it, learn its directions and move with its tensions. If resistance does emerge, the worker should help the male client to shift his/her perceptions by reframing his thoughts to create a new momentum towards change. It is important for the worker to empower men to find solutions to their own problems and elicit self-motivational statements. When workers use this approach, the resistance tends decrease rather than increase, as men are not reinforced for becoming argumentative and playing "devil's advocate" to the worker's suggestions. The motivational interviewing approach encourages clients to develop their own solutions to the problems that they have self-defined. This reduces the sense that there is a power hierarchy in the client-worker relationship that the client needs to resist. When exploring the issues of men, workers may invite men to examine new perspectives, but workers do not impose new ways of thinking on them. For example, when a male client told the worker that "I don't like the idea of paying child support to my ex-wife because I don't know how she is going to spend it" the worker chose to roll with the resistance and responded with an empathic reply "It upsets you to be unable to decide how child support money is spent." This response lessens the likelihood of an argument between the worker and the client and may decrease the level of resistance men feel toward the worker and the overall helping process.

\section{Challenge 5: Masculine Gender Role Strains}

Practitioners who work with men will inevitably encounter clients whose issues can be traced to their effort to live up to masculine ideals (Addis \& Mahalik, 2003). This may be the case for the nonresidential father seen individually because of feelings of inadequacy as a father, the male client seen in couples counseling because his partner complains he is emotionally distant, or the male client seen in family counseling because family members complain he is never home. In each of these cases, the practitioner working with the male client will be "better prepared to intervene effectively if he or 


\section{Glenn Stone - Working with Men}

she can assess how the male client's internalized masculinity ideals contribute to his presenting problems" (Mahalik, 1999, p. 333).

According to Pleck (1995), gender role strain occurs because stereotyped societal norms around gender ideals are often contradictory, inconsistent, and unattainable. Pleck further contends that the consequences of violating these social norms are more severe for men than women as the emotional and relational disconnection that men are socialized to enact is associated works in such a way to create a wide range of psychological and interpersonal problems.

During the last 20-30 years, scholars (e.g., O’Neil, 1982) have identified a number of gender roles associated with traditional masculinity that contribute to gender role strain. Mahalik (1999) identifies several areas of salient gender role messages for men that may contribute to psychological issues for men. We will identify four (4) of these and explore their impact men.

Power. Men are taught that it is vital to be powerful in all aspects of their lives: physically, financially, sexually, interpersonally, and intellectually (Harris, 1995). The male socialization process teaches men to be "in charge" and to maintain control over others in their personal and professional lives (O'Neil, 1982). They are taught to compete against others to "win" not just for status but in order to be in control.

These issues related to power are common challenges for the men dealing with relationship issues in life. For example, a divorcing father may experience the legal procedures of divorce as a disempowering process in which others have significant power and control over the terms of custody, parenting time, child support, etc. (Stone \& McKenry, 1998). It can be very difficult for these men to maintain a sense of power within their lives.

Workers serving men will need to assist them to express their feelings of powerless and help them develop a consistent "narrative" that explains the reasons and circumstances for the end of the relationship (Wall \& Levy, 1994). Such explanations may ease their sense of powerlessness and help them grapple with the "why" question related to the break-up. Effective narratives include attributing the responsibility for the break up to both partners, and an acceptance that the decision to separate made sense given the situation (Wall 
\& Levy, 1994). The ability to establish such narratives may ultimately help men develop a constructive relationship with their former partner. Such a relationship may ultimately help them gain an increased sense of "power" and "control" in their life.

Emotional control. According to Harris (1995), men are taught that it is important to be in control of themselves emotionally, and they are socialized to be patient and uncomplaining and to hide their emotions, especially "weak" ones. They are discouraged from acknowledging that they may possess "feminine" elements to their personalities and become somewhat frightened by the idea that they might have feelings that seem womanly. The impact of this socialization process is significant as "men who rigidly adhere to this masculine identity tend to have difficulty telling others they care about them, disclosing and discussing vulnerabilities, and finding words to describe their feelings" (Mahalik, 1999, p. 335). As a result, these men

give little time and attention to their emotional or inner life, feel uncomfortable being demonstrative or taking care of their children, and feel that if they express their strong feelings that they will be open to attack by other people (Mahalik, 1999, p. 335).

These internalized beliefs will make it difficult for me to seek assistance for adjustments they need to make throughout their lives. The beliefs will make it difficult for men to work through typical feelings of grief, loss, anger, loneliness, etc. that are experienced by all as we deal with various challenges in our personal and professional lives.

Primacy of work. Men are told in many subtle and not-so-subtle ways that work is the most important part of their identity (Riley, 2003). They are socialized to put their work goals ahead of their personal relationships with family and are shown models from other men-often their own men-that it is necessary to sacrifice family relationships in order to get ahead. Because of this socialization, men have difficulty with family members making demands on their time and energy that take away from work goals, and give little time to their own physical or familial well-being (Meth, et al., 1991). Men often 


\section{Glenn Stone - Working with Men}

feel uncomfortable when attending to family matters because they worry about how it will affect the job and feel open to attack when family or important others question their absence or noninvolvement in their families.

Self-reliance. Men are often instructed that it is important not to look for help from anyone other than oneself and are socialized to do things alone and not rely on others (Keohane \& Richardson, 2018). They are taught that it is important to take care of their own problems and that a man does not let others tell him what to do. Men often have difficulty with asking for help or admitting that they do not know or cannot do something and feel uncomfortable with taking charity or getting help from others when they are having difficulty. Keohane \& Richardson (2018) found that one way to deal with the issue of men being overly self-reliant is to negotiate ways to for me to ask for help and in turn to accept help from providers. They also noted the importance of flexibility on part of the worker in the manner in which help is offered. They noted the importance of offering up and providing services in a manner that does not compromise masculinity. In their study they found that "men asking for, and accepting the offer of help, was legitimized in circumstances where personal problems were perceived to have reached a certain threshold of distress" (p. 164). This might mean that workers might need to be receptive to men seeking help only at the point of a self-perceived crisis. That may call for the worker to suspend judgment and accept the need for some men to reach a point of exhausting all personal resources before asking for assistance in order to maintain their sense of self-reliance.

\section{Conclusion}

The purpose of this paper is to advocate for gender-sensitive practice for men in our efforts to address behavioral health issues. Research over the years has shown that men have unique problems and needs, as well as distinctive way of showing that they are experiencing distress (e.g., Baum, 2003). In order to best address these special needs of men in distress it seems necessary to develop and implement a form of practice that is sensitive to the special issues that men bring to the helping process. 
As Baum (2016) notes, the need for change in our helping techniques with men should be focused on the core value of an "equal, non-discriminatory approach to every person and group in need" (p. 1469). This paper puts forth a framework for a gender-sensitive practice model that could be used in working with men. It provides insights into the various challenges that men pose for workers attempting to provide assistance. There are also suggestions on how workers might address some of these challenges. As Baum (2017) suggests, it is possible to train workers on how to engage in gender-sensitive work with men. However, this will take a commitment from helping professionals to do so. While this paper provides a rudimentary framework for this type of practice, it is acknowledged that much research in this area needs to be accomplished. However, it is important that we start to investigate and implement different helping models in our practice with men.

\section{References}

Addis, M.E., \& Mahalik, J.R. (2003). Men, masculinity, and the contexts of help seeking. American Psychologist, 58(1), 5-14. doi: 10.1037/0003066X.58.1.5

Bandura, Albert (1962). Self-efficacy mechanism in human agency.

American Psychologist. 37(2): 122-147. doi: 10.1037/0003-

066X.37.2.122

Baum, N. (2003). The male way of mourning divorce: When, what and how. Clinical Social Work Journal, 31(1), pp. 37-50. doi:

10.1023/A:1021462517875

Baum, N. (2016). The unheard gender: The neglect of men as social work clients. British Journal of Social Work, 46, 1463-1471. doi:

10.1093/bjsw/bcv074

Baum, N. (2017). Gender-sensitive intervention to improve work with fathers in child welfare services. Child and Family Social Work, 22, 419 427. doi: 10.1111/cfs.12259 
Baumeister, R. F., \& Sommer, K. L. (1997). What do men want? Gender differences and two spheres of belongingness: Comment on Cross and Madson. Psychological Bulletin, 122(1), 38-44.

Chesler, P. (1972). Women and madness. San Diego: Harcourt Brace Jovanich.

Collins, D., Jordan, C., \& Coleman, H. (2009). An Introduction to Family Social Work. Itasca, IL: F. E. Peacock.

Cusack, J., Deane, F., Wilson, C., \& Ciarrochi, J. (2004). Who influences men to go to therapy? Reports from men attending psychological services. International Journal for the Advancement of Counselling, 26(3), 271-283. doi: 10.1023/B:ADCO.0000035530.44111.a8

Englar-Carlson, M., Evans, M., \& Duffey, T. (2014). A counselor's guide to working with men. New York, NY: Wiley.

Eriksen, K., \& Kress, V. E. (2008). Gender and diagnosis: Struggles and suggestions for counselors. Journal of Counseling \& Development, 86(2), 152-162. doi: 10.1002/j.1556-6678.2008.tb00492.x

Fish, L. S., New, R. S., Van Cleave, N. J. (1992). Shared parenting in dualincome families. American Journal of Orthopsychiatry, 62, 83-92. doi: 10.1037/h0079306

Fong, J. \& Walsh, R. (1998). Voices of the blamed: Mothers' responsiveness to father-daughter incest, Journal of Family Social Work, 3(1), 2541. doi: 10.1300/J039v03n01_03

Grossmann, K., Grossman, K. E., Fremmer-Bombik, E., Kindler, H., Scheuerer-Englisch, H., \& Zimmermann, P. (2002). The uniqueness of the child-father attachment relationship: Fathers' sensitive and challenging play as a pivotal variable in a 16-year longitudinal study. Social Development, 11(3), 301-337. doi: 10.1111/1467-9507.00202 Harris, I. M. (1995). Messages men hear: Constructing masculinities. Bristol, PA: Taylor and Francis.

Heatherington, L., Stets, J., \& Mazzarella, S. (1986). Whither the bias: The female client's "edge" in psychotherapy? Psychotherapy, 23, 252-256. doi: 10.1037/h0085606 
Heppner, P. P. \& Gonzales, D. S. (1987). Men counseling men. In M. Scher, M. Stevens, G. Good and G. A. Eichenfield (eds.), Handbook of counseling and psychotherapy with men (pp. 30-38). Newbury Park, CA: Sage.

Hepworth, D. H., Rooney, R. H., Rooney, G. D., Strom-Gottfried, K., \& Larsen, J. (1997). Direct social work practice: Theory and skills. Pacific Grove, CA: Brooks/Cole Publishing.

Holmes, M. (2015). Men's emotions: Heteromasculinity, emotional reflexivity, and intimate relationships. Men \& Masculinities, 18(2), 176192. doi: 10.1177/1097184X14557494

Hook, D. (2003). Psychotherapy and 'ethical sensibility': Towards a history of criticism. International Journal of Psychotherapy, 8(3), 195-212. doi: 10.1080/13569080310001655313

Hyde, J. S. (2005). The gender similarities hypothesis. American Psychologist, 60(6), 581-592. doi: 10.1037/0003-066X.60.6.581

Jordan, P. (1993). Counseling men confronted by marital separation. Journal of Divorce and Remarriage, 18(1-2), 109-126. doi:

https://doi.org/10.1300/J087v18n01_05

Keohane, A., \& Richardson, N. (2018). Negotiating gender norms to support men in psychological distress. American Journal of Men's Health, 12(1), 160-171. doi: 10.1177/1557988317733093

Knudsen-Martin, C. (2013). Why power matters: Creating a foundation of mutual support in couple relationships. Family Process, 52(1), 5-18. doi: 10.1111/famp.12011

Levant, R. F. (2011). Research in the psychology of men and masculinity using the gender role strain paradigm as a framework. American Psychologist, 66(8), 765-776. doi: 10.1037/a0025034

Levant, R.F., \& Pollack, W.S. (Eds.). (1995). A new psychology of men. New York: Basic Books.

Mahalik, J. (1999). Incorporating a gender role strain perspective in assessing and treating men's cognitive distortions. Professional Psychology: Research and Practice, 30, 333-340. doi: 10.1037/07357028.30.4.333 
Meth, R., Pasick, R., Gordon, B., Allen, J., Feldman, L., \& Gordon, S. (1991). Men in therapy: The challenge of change. New York, NY: Guilford Press.

Miller, W. R. \& Rollnick, S. (2002). Motivational Interviewing: Preparing people to change addictive behavior. New York, NY: Guilford.

Miller, W. R., Zweben, A., DiClemente, C. C., \& Rychtarik, R. G. (1992).

Motivational Enhancement Therapy manual: A clinical research guide for therapists treating individuals with alcohol abuse and dependence.

Rockville, MD: National Institute on Alcohol Abuse and Alcoholism.

Moyers, T. B. (2014). The relationship in motivational interviewing. Psychotherapy, 51(3), 358-363. doi: 10.1037/a0036910

Musick, K., Meier, A., \& Flood, S. (2016). How parents fare: Mothers' and fathers' subjective well-being in time with children. American Sociological Review, 81(5) 1069-1095. doi: 10.1177/0003122416663917 Norman, J., \& Wheeler, B. (1996). Gender-sensitive social work practice: A model for education. Journal of Social Work Education, 32, 203-213, doi: 10.1080/10437797.1996.10778451

O'Neil, J. M. (1982). Gender role conflict and strain in men's lives: Implications for psychiatrists, psychologists, and other human service providers. In K. Solomon \& N. B. Levy (Eds.), Men in transition: Changing male roles, theory, and therapy (pp. 5-44). NY: Plenum. Patrick, S., \& Beckenbach, J. (2009). Male perceptions of intimacy: A qualitative study. Journal of Men's Studies, 17(1), 47-56. doi:

10.3149/jms.1701.47

Pleck, J. H. (1995). The gender role strain paradigm: An update. In R. F.

Levant \& W. S. Pollack (Eds.), The new psychology of men (pp. 11-2). New York: Basic Books.

Riley, S. E. (2003). The management of the traditional male role: A discourse analysis of the constructions and functions of provision. Journal of Gender Studies, 12(2), 99-113. doi: 10.1080/0958923032000088300

Robertson, J. M., \& Fitzgerald, L. F. (1990). The (mis)treatment of men. Effects of client gender role and life-style on diagnosis and attribution of 
pathology. Journal of Counseling Psychology, 37, 3-9. doi:

10.1037/0022-0167.37.1.3

Saleeby, D. (ed.) (1992). The strengths perspective in social work practice.

New York: Longman.

Scher, M. (1979). On counseling men. Journal of Counseling and

Development, 57(5), 252-254. doi: 10.1002/j.2164-4918.1979.tb05157.x

Seidler, Z. E., Rice, S. M., River, J., Oliffe, J. L., \& Dhillon, H. M. (2018).

Men's mental health services: The case for a masculinities model. Journal of Men's Studies, 26(1), 92-104. doi: 10.1177/1060826517729406

Snarey, J. R. (1993). How fathers care for the next generation: A fourdecade study. Boston, MA: Harvard University Press.

doi:10.4159/harvard.9780674365995

Stone, G., \& McKenry, P. (1998). Nonresidential father involvement: A test of a mid-range theory. Journal of Genetic Psychology, 159, 313-336. doi: 10.1080/00221329809596154

Toews, M. L., \& Bermea, A. M. (2017). "I was naive in thinking, 'I divorced this man, he is out of my life"': A qualitative exploration of postseparation power and control tactics experienced by women. Journal of Interpersonal Violence, 32(14), 2166-2189. doi:

$10.1177 / 0886260515591278$

Veach, T. (1998). Child sexual offenders' attitudes toward punishment, sexual contact, and blame. Journal of Child Sexual Abuse, 7(4), 43-58, doi: 10.1300/J070v07n04_04

Vogel, D, L., Epting, F., Wester, S.R. (2003). Counselors' perceptions of female and male clients. Journal of Counseling \& Development, 81, 131141. doi: 10.1002/j.1556-6678.2003.tb00234.x

Wall, J.C. and Levy, A.J. (1994). Treatment of non-custodial fathers: Gender issues and clinical dilemmas. Child and Adolescent Social Work Journal, 11 (4): 295-313. doi: https://doi.org/10.1007/BF01876556 Wilcox, D. W., \& Forrest, L. (1992). The problems of men and counseling: Gender bias or gender truth? Journal of Mental Health Counseling, 14(3), 291-304. Retrieved from: https://psycnet.apa.org/record/199302483-001 
52 Glenn Stone - Working with Men

Dr. Glenn Stone is Department chair of the department of social work at the Ball State University, United States.

Contact Address: Direct correspondence to Dr. Glenn Stone, Ball State University, Departament of Social Work, 2000 West University

Muncie, IN 47304, email: gestone@bsu.edu 